\title{
Editorial
}

\section{Committed to examining our roles: clinic for communities and students}

Elaine Hall

Northumbria University, UK

Elaine.Hall@northumbria.ac.uk

Clinic has so many possibilities and while this is enticing and engaging for academics and students alike, it is clear that a naïve commitment to clinic can lead to unintended problems when the needs of various stakeholders come into conflict. All the papers in this edition contribute to the growing sophistication of our clinic discourse, critically examining the intents, processes and positions of the actors involved.

We begin with a perspective from sociology: Diana Pan's research enables us to explore the student experience of work and identity. This is not a paper specifically about clinic, nevertheless it offers us a wider view and her rich qualitative data and theoretical framing will have an impact on how we understand our students' engagement with clinic.

The needs of communities are both desperately sought and difficult to acquire:

Shristi Banerjee, Raveena Rao Kallakuru, Ambedkar Bhavan, Yamini Kumar, 
Maithili Pai, Nirmal Kumar Upreti and David Tushaus have a rich account of research design, community engagement and collaborative understanding of domestic violence across contexts that reflects both on practical and ethical issues.

In understanding what we do and why we do it, sometimes it is helpful to return to the beginning and in this issue we have both a narrative and an analysis based in South Africa from Donald Nicholson which teases out a number of elements in clinic design that could be, have been but perhaps, need not be in conflict with one another. This piece will be a reference point for our work on the intent and purpose of clinic and I happily foresee what the late Caroline Aherne dubbed 'heated debate'.

As a companion to this, Rebecca Grimes provides a vivid report from the Ed O'Brien Memorial Conference in South Africa, where the latest in Streetlaw from across the world was showcased. This will serve to whet your appetite for our practice reports: Michal Urban and Hana Draslarová bring us up to date with a long-running collaboration with the Roma community in the Czech Republic and Farzana Akter indicates the impact of influential work from India to Bangladesh.

My usual plug for upcoming events in the CLE world:

- In October the European Network for Clinical Legal Education (ENCLE) will host its 4th annual conference on 27th and 28th October 2016 (2 days Conference) at the Faculty of Law, University of Valencia, Valencia (Spain). The conference, entitled "Clinical Legal Education and Access to Justice for 
all: from asylum seekers to excluded communities", aims to bring clinicians together from across Europe to discuss all aspects of teaching and learning, learn from each other and share best practices on how to improve the access to justice to, in particular, vulnerable persons, through clinical legal education. The ENCLE Conference will be - as usual - open to all kinds of CLE activity focuses. However, given the on-going influx of refugees in Europe and the fact that more and more law clinics are focusing their work on the support to refugees and asylum seekers, ENCLE is particularly encouraging papers dealing with CLE and access to justice for refugees and asylum seekers. Proposals for either paper presentations or workshops should be sent to encle.info@gmail.com by 31 ${ }^{\text {st }}$ August 2016.

Meanwhile I'm heading off to the IJCLE conference with the Association for Canadian Clinical Legal Education (ACCLE). The conference, which will be hosted by the University of Toronto from 10-12 July, is entitled The Risks and Rewards of Clinic and encourages participants to reflect on the balance between risk and reward for all the stakeholders in clinic. We have a fantastic range of papers, seminars and symposia and I'm delighted to announce that we have managed to secure Sarah Buhler and Adrian Evans as keynote speakers. Papers from this conference will be available on the Legal Education and Professional Skills Research Group website www.northumbria.ac.uk/leaps . 
This will be followed by the International Legal Ethics Conference VII (ILEC VII), which Fordham Law School will host in New York City on July 14-16, 2016 focusing on legal education, ethics, technology, regulation, globalization and rule of law (www.law.fordham.edu/ilec2016). I look forward to catching up with many of you in the next week! 